\title{
Commentary: Conduits and congenital heart surgery- ka-ching and more ka-ching
}

\author{
Ronald K. Woods, MD, PhD
}

\footnotetext{
From the Division of Pediatric Cardiothoracic Surgery, Department of Surgery, Medical College of Wisconsin, and Herma Heart Institute, Children's Hospital of Wisconsin, Milwaukee, Wis

Disclosures: Dr Woods is co-founder of OperVu, Inc, which has no relationship to the content of this work.

Received for publication July 11, 2019; accepted for publication July 12, 2019; available ahead of print Aug 20, 2019.

Address for reprints: Ronald K. Woods, MD, PhD, Division of Pediatric Cardiothoracic Surgery, Department of Surgery, Medical College of Wisconsin, Children's Hospital of Wisconsin, 9000 W Wisconsin Ave MS B 730, Milwaukee, WI 53226 (E-mail: rwoods@chw.org).

J Thorac Cardiovasc Surg 2020;159:e77

$0022-5223 / \$ 36.00$

Copyright (c) 2019 by The American Association for Thoracic Surgery

https://doi.org/10.1016/j.jtcvs.2019.07.051
}

Dalziel and colleagues very eloquently and efficiently show substantial financial cost associated with right ventricle to pulmonary artery conduits placed early in life. ${ }^{1}$ In their program, total costs in the first decade of life (approximately USD \$200,000) were similar to those of patients with staged palliation of single-ventricle heart disease. Despite a seemingly prolonged index length of stay and the obvious influence on cost, the underlying message remains valid and important. In fact, a lot of what we do in the neonatal and infant population is associated with substantial cost. Smith and colleagues reported an approximate cost of USD $\$ 150,000$ for an admission for major neonatal heart surgery $\left(2011\right.$ cost). ${ }^{2}$ Burstein and colleagues reported cost approaching USD $\$ 800,000$ for a heart failure admission associated with implantation of a ventricular assist device. ${ }^{3}$ It is challenging to comprehend what an analysis would show if costs were tracked from the antenatal period out through the fifth or sixth decade of life.

The provision of higher quality care at lower costs-easy to state as a goal, not so easy to fully operationalize. Are quality and cost evaluated only for the index admission, first year, first decade, more? Consider a very complex newborn case with a poor prognosis even were care to be excellent. An intraoperative catastrophe and death in the operating room would seem to be associated with very low quality, but also low cost. What if the surgery goes very well, the child stays 3 months in the hospital, and is discharged with a tracheostomy and neurologic injury? The latter course avoided death, but incurred substantial cost. Even if we had very clean definitions of quality and appropriate weighting measures that might shed light on the former question, valid costing continues to be a process in evolution. The data provided by sophisticated costing software is an important step forward, yet institutions continue to

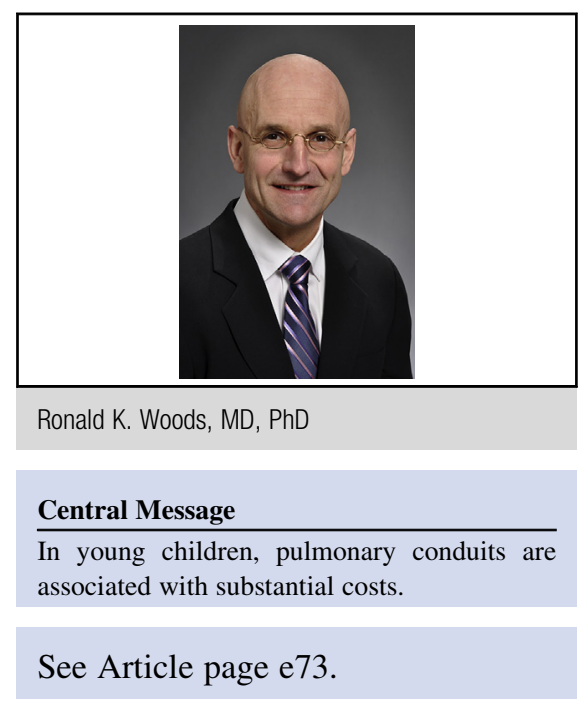

strive to refine their knowledge of exactly what it costs to provide a specific service.

This all occurs in a very complex background of payer contracting; variable reimbursement, confidentiality clauses with payers (institution A cannot inform institution $\mathrm{B}$ of charges and reimbursements for insurance company C), the uncertainty in future reimbursement schemes, and a national mandate for price transparency. I sat down with our executive director for a brief lesson on these topics and looks at possible future scenarios-I left bewildered and amazed and very happy that I am not a vice president of finance. Perhaps, one thing we as surgeons can do is insist that we be educated on our specific procedural costs. For example, if my intraoperative costs for an arterial switch exceed those of my two partners, I need to look at my outlier elements and be willing to consider change. And, in an ideal world, this process would extend across disciplines and institutions. Doing nothing will simply result in more ka-ching.

\section{References}

1. Dalziel K, Huang L, Saxena A, Winlaw DS. Utilization of hospital inpatient resources by children requiring a right ventricle-to-pulmonary artery conduit in the first 10 years of life. J Thorac Cardiovasc Surg. 2020;159:e73-5.

2. Smith AH, Gay JC, Patel NR. Trends in resource utilization associated with the inpatient treatment of neonatal congenital heart disease. Congenit Heart Dis. 2014;9:96-105.

3. Burstein DS, Shamszad P, Dai D, Almond CS, Price JF, Lin KY, et al. Significan mortality, morbidity and resource utilization associated with advanced heart failure in congenital heart disease in children and young adults. Am Heart J. 2019; 209:9-19. 